\title{
Use of Functionalized Resin for Matrix Separation and Trace Elements Determination in Petroleum Produced Formation Water by Inductively Coupled Plasma Mass Spectrometry
}

\author{
Ricardo Erthal Santelli, ${ }^{1}$ Aline Soares Freire, ${ }^{1}$ Eliane Padua Oliveira, ${ }^{2}$ \\ Valfredo Azevedo Lemos, ${ }^{3}$ Cléber Galvão Novaes, ${ }^{3}$ and Marcos Almeida Bezerra ${ }^{3}$ \\ ${ }^{1}$ Instituto de Química, Universidade Federal do Rio de Janeiro, Avenida Athos da Silveira Ramos 149, Cidade Universitária, \\ 21941-909 Rio de Janeiro, RJ, Brazil \\ ${ }^{2}$ Divisão de Química Analítica, Instituto Nacional de Tecnologia, Avenida Venezuela 82, 20081-312 Rio de Janeiro, RJ, Brazil \\ ${ }^{3}$ Laboratório de Química Analítica, Universidade Estadual do Sudoeste da Bahia, Rua José Moreira Sobrinho s/n, \\ Jequié 45206-190, BA, Brazil \\ Correspondence should be addressed to Ricardo Erthal Santelli, resantelli@globo.com
}

Received 25 August 2011; Accepted 4 October 2011

Academic Editors: A. Angioni, A. M. Haji Shabani, D. Kara, and I. Lavilla

Copyright ( $) 2012$ Ricardo Erthal Santelli et al. This is an open access article distributed under the Creative Commons Attribution License, which permits unrestricted use, distribution, and reproduction in any medium, provided the original work is properly cited.

This work approaches the development of a procedure for separation and determination of five trace metals $(\mathrm{Co}, \mathrm{Cd}, \mathrm{Pb}, \mathrm{Ni}$, and $\mathrm{Cu}$ ) from petroleum produced formation water. This procedure uses a styrene divinyl-benzene polymeric resin modified with 4-(5'-bromo-2' -tiazolilazo) orcinol, and the determination was performed by inductively coupled plasma mass spectrometry. A response surface methodology using a Doehlert matrix was used to optimize the solid-phase extraction of the studied elements. By using $50.0 \mathrm{~mL}$ of sample solution for separation/preconcentration, limits of quantification of 2.4, 14, 10, 11, and $350 \mathrm{ng} \mathrm{L}^{-1}$ were obtained for $\mathrm{Co}, \mathrm{Cd}, \mathrm{Pb}, \mathrm{Ni}$, and $\mathrm{Cu}$, respectively. The developed procedure was applied for determination of these trace elements in produced formation water from offshore platforms in the Brazilian Northeast.

\section{Introduction}

Produced formation water (PFW) is a complex mixture consisting of formation water with injection water, solids, residual hydrocarbons, naturally occurring radioactive material, metals in the form of inorganic salts, and chemical residuals from the production. These residuals are obtained when sea water is injected into the deposit rock to help force oil to the surface and ultimately increase oil production. Once it is brought to the surface, the water is separated from the hydrocarbons and treated to remove oil, and additional chemicals are added to the produced formation water as needed. The effluent is then discharged into the sea or injected back into the wells or other suitable geological formations, with or without further treatment. Production chemicals used in the oil production process include corrosion inhibitors, scale inhibitors, biocides, oxygen scavengers, demulsifiers or deoilers, antifoamers, viscosifiers, hydrate inhibitors, cleaners and emulsion breakers. These substances also contribute to the modification of the chemical composition of the original matrix [1-3].

The volume of PFW at offshore oil platforms is, generally, several times greater than that of oil. Thus, offshore oil production frequently results in environmental discharge of drill cuttings and produced formation water contaminated with residuals of exploration and production, chemicals, and formation chemicals. Chemical substances present in produced formation water are the focus of management activity, including total hydrocarbon content (THC), aromatics (PAHs, BTEX, and naphthalene), organic acids and phenols; alkylphenols (two groups: $\mathrm{C} 1-\mathrm{C} 3$ and $\mathrm{C} 4-\mathrm{C} 9$ ); toxic metals (arsenic, lead, cadmium, copper, chromium, mercury, nickel, zinc); radionuclides; and production chemical residuals. Thus, toxic metal quantification in production formation waters is of environmental concern [3-6]. 
Inductively coupled plasma mass spectrometry (ICPMS) is becoming a frequently employed analytical technique for its good analytical performance characteristics, such as low limits of detection, multielemental capabilities, wide dynamic range, and capacity to perform isotopic analysis with high sensitivity for most elements. However, using this technique to directly analyze saline samples, such as produced formation waters, can be very troublesome due to severe interferences caused by matrix components.

Although the detection capacity of ICP-MS permits the direct determination of trace metals at sub-ng $\mathrm{mL}^{-1}$ levels, spectroscopic (caused by polyatomic species) and nonspectroscopic (due to the high content of dissolved solids) interferences make the direct analysis of these samples difficult $[7,8]$.

Recent studies have presented various pretreatment techniques to overcome the problems generated by complex matrixes in ICP-MS. In all of these techniques, the aim is to separate and/or preconcentrate the analyte in order to improve the detection limit and reduce matrix content, thereby enhancing analytical conditions. Much of the literature recommends the use of offline or online separation and preconcentration systems as means of reducing or eliminating spectroscopic and non-spectroscopic interferences in ICP-MS for analysis of samples with a high saline content [811].

Solid-phase extraction (SPE) is a very important technique for metal separation and its determination at trace levels. SPE has specific advantages, including simplicity, reliability, good metal loading capacity, and the ability to obtain high enrichment factors $[12,13]$. Versatile systems have been obtained by applying solid supports loaded or functionalized with complexing reagents [14-16]. These systems have been applied for preconcentration and determination of metals in a wide range of samples [17-19]. A notable advantage of chemically functionalizing a resin is the reduction of leaching of the ligand from the support. This increases lifetime and it maintains good analytical features for the developed systems [20]. Br-TAO has been synthesized for the first time and applied in an online cloud point extraction procedure for determination of $\mathrm{Mn}$ [21].

In this study, a multivariate technique (Doehlert design) was used to develop a procedure based on solid-phase extraction to separate and preconcentrate trace metals from produced formation water (PFW). These PFW samples were collected from offshore platforms in the Brazilian Northeast. Finally, metals determination were made using ICP-MS. This procedure is based on solid-phase extraction of metals in an offline minicolumn. The column was packed with Amberlite XAD-4 polymeric resin chemically modified with the $4-\left(5^{\prime}-\right.$ bromo-2' -thiazolylazo) orcinol ( $\mathrm{Br}-\mathrm{TAO})$ reagent and trace metals were re-extracted using a nitric acid solution.

\section{Experimental}

2.1. Instrumentation. An X Series II quadrupole ICP-MS (Thermo Fisher Scientific, Bremen, Germany), with a Peltiercooled impact bead spray chamber and a concentric glass
TABLE 1: Instrumental parameters used for the analytes determination by ICP-MS after solid-phase extraction.

\begin{tabular}{lc}
\hline \multicolumn{2}{c}{ ICP-MS operating parameters setting } \\
\hline Cool gas flow $\left(\mathrm{L} \mathrm{min}{ }^{-1}\right)$ & 13 \\
Auxiliary gas flow $\left(\mathrm{L} \mathrm{min}^{-1}\right)$ & 0.8 \\
Nebulizer gas flow $\left(\mathrm{L} \mathrm{min}^{-1}\right)$ & 0.95 \\
Plasma power $(\mathrm{W})$ & 1400 \\
Sample uptake rate $\left(\mathrm{mL} \mathrm{min}^{-1}\right)$ & 0.90 \\
Resolution & 300 \\
Analytes (measured isotopes) & ${ }^{60} \mathrm{Ni},{ }^{59} \mathrm{Co},{ }^{65} \mathrm{Cu},{ }^{111} \mathrm{Cd}$ and ${ }^{208} \mathrm{~Pb}$ \\
Internal standards & ${ }^{45} \mathrm{Sc},{ }^{72} \mathrm{Ge},{ }^{103} \mathrm{Rh},{ }^{115} \mathrm{In}$ \\
Dwell time (ms) & 10 \\
Channels per AMU & 1 \\
Data acquisition mode & Continuous acquisition \\
Runs & 3 \\
Spray chamber & Glass impact bead \\
Nebulizer & Meinhard glass concentric \\
\hline
\end{tabular}

nebulizer, was used for all analyte measurements. An autosampler ASX-510 (CETAC, Omaha, NE, USA) was used for sample handling. The spectrometer was operated in the standard mode and PlasmaLab software was used for data acquisition. Standard mode corresponds to the highest available sensitivity and is used to quantify elements whose interferences can be reduced through instrument tuning. A tuning solution with $10 \mu \mathrm{g} \mathrm{L}^{-1}$ of $\mathrm{Ba}, \mathrm{Be}, \mathrm{Bi}, \mathrm{Ce}, \mathrm{Co}$, In, $\mathrm{Li}, \mathrm{Ni}, \mathrm{Pb}$, and $\mathrm{U}$ was employed to obtain minimum ratios of interference (polyatomic, isobaric, doubly charged, and oxide-based spectral interferences).

To correct analyte signal fluctuations, a mixture of internal standards ( $\mathrm{Sc}, \mathrm{Ge}, \mathrm{Rh}$, and In) was added to standards and samples in $50 \mu \mathrm{g} \mathrm{L}^{-1}$ concentrations. The trace metal determinations were carried out under the conditions presented in Table 1. This mixture is used as universal internal standard in our laboratory because it allows correcting the signal fluctuation of several elements.

A peristaltic pump C-6 XV (Alitea, Stockholm, Sweden) furnished with Tygon tubes was used to pump all solutions to preconcentration through the minicolumn loaded with the solid phase.

2.2. Reagents, Solutions, and Materials. All reagents were prepared using ultrapure water (Elix and Synergy, Millipore, Bedford, MA, USA) and analytical grade chemicals. Nitric acid was of Suprapur quality (Merck, Darmstadt, Germany). New polyethylene recipients and graduate tubes were used in all steps, to avoid contamination. These were kept overnight in 10\% nitric acid solution. Before use, these flasks were rinsed with ultrapure water and dried in a dust-free environment (laminar flow cabinet).

Cobalt, $\mathrm{Cd}, \mathrm{Pb}, \mathrm{Ni}, \mathrm{Cu}, \mathrm{Sc}, \mathrm{Ge}, \mathrm{Rh}$, and In solutions were prepared by diluting $1000 \mathrm{mg} \mathrm{L}^{-1}$ standard solutions (CertiPrep SPEX, Metuchen, USA).

$\mathrm{NaCl}$ solutions were prepared from dissolution of the solid reagent (Merck, Germany) in ultrapure water. 
A $1.0 \mathrm{~mol} \mathrm{~L}^{-1}$ TRIS (tris(hydroxymethyl)aminomethane) buffer solution ( $\mathrm{pH}$ in the range 7 to 9) was prepared by dissolving $6.88 \mathrm{~g}$ of its sodium salt and concentrate nitric acid (about $2.5 \mathrm{~mL}$ ) in ultrapure water to a final volume of $50 \mathrm{~mL}$ and $\mathrm{pH}$ adjusted with the same acid before to complete the volume in a volumetric flask. Acetate $(\mathrm{pH} \mathrm{5.0)}$ and citrate $(\mathrm{pH}$ 6.0) buffers also were used in the optimization step.

A $1.0 \mathrm{~mol} \mathrm{~L}^{-1} \mathrm{HNO}_{3}$ for re-extraction of trace metals from minicolumn was made from Suprapur quality.

Amberlite XAD-4 (specific surface area $330 \mathrm{~m}^{2} \mathrm{~g}^{-1}$ and bead size 20-60 mesh), a polystyrene divinylbenzene copolymer, was purchased from Aldrich (Milwaukee, WI, USA).

\subsection{Synthesis of the 4-(5'-Bromo-2'-thiazolylazo $)$ Orcinol} $(B r-T A O)$. For Br-TAO preparation, a modified procedure was performed, based on the synthesis of similar reagents $[22,23]$. 2-Amino-5-bromothiazole $(2.0 \mathrm{~g})$ was dissolved in $50 \mathrm{~mL}$ of a $6.0 \mathrm{~mol} \mathrm{~L}^{-1}$ hydrochloric acid solution at $0-5^{\circ} \mathrm{C}$. A solution of $0.53 \mathrm{~g}$ of sodium nitrite in $20 \mathrm{~mL}$ of water was added dropwise. The mixture was stirred and kept at 0 $5^{\circ} \mathrm{C}$ for $45 \mathrm{~min}$. For coupling, $0.96 \mathrm{~g}$ of orcinol was added to $20 \mathrm{~mL}$ of $1.0 \mathrm{~mol} \mathrm{~L}^{-1}$ sodium carbonate solution and the mixture was cooled to $0-5^{\circ} \mathrm{C}$. This solution was added dropwise to the above diazotized compound at vigorous stirring. The system was allowed to stand overnight in a refrigerator at $0-5^{\circ} \mathrm{C}$. The product was filtered and rinsed with cold water. A dark-red precipitate resulted and was purified by recrystallization in ethanol with activated carbon [21]. The solution of $\mathrm{Br}-\mathrm{TAO}$ was prepared by dissolving $0.5 \mathrm{~g}$ of reagent in $250 \mathrm{~mL}$ of a $5 \%(\mathrm{w} / \mathrm{v}) \mathrm{NaOH}$ solution.

2.4. Functionalization of the XAD-4 Resin with Br-TAO Reagent. Amberlite XAD-4 (5 g) was treated with $10 \mathrm{~mL}$ of concentrated $\mathrm{HNO}_{3}$ and $25 \mathrm{~mL}$ of concentrated $\mathrm{H}_{2} \mathrm{SO}_{4}$ and stirred at $60^{\circ} \mathrm{C}$ for $1 \mathrm{~h}$ in a water bath. The reaction mixture was then poured into an ice-water mixture. The nitrated resin was filtered, washed repeatedly with water until free acid was formed, and treated with a reducing mixture of tin (II) chloride, concentrated hydrochloric acid, and ethanol. The system was refluxed for $12 \mathrm{~h}$ at $90^{\circ} \mathrm{C}$. The precipitate was filtered and washed with water, $2 \mathrm{~mol} \mathrm{~L}^{-1} \mathrm{HCl}$ and $2 \mathrm{~mol} \mathrm{~L}^{-1}$ $\mathrm{NaOH}$. The amino resin was first washed with $2 \mathrm{~mol} \mathrm{~L}^{-1} \mathrm{HCl}$ and finally with ultra-pure water to remove excess $\mathrm{HCl}$. This was suspended in an ice-water mixture $(150 \mathrm{~mL})$ of $1 \mathrm{~mol} \mathrm{~L}^{-1}$ $\mathrm{HCl}$ and $1 \mathrm{~mol} \mathrm{~L}^{-1} \mathrm{NaNO}_{2}$. The diazotized resin was filtered, washed with ice-cold water, and reacted with an alkaline solution of $\mathrm{Br}-\mathrm{TAO}$ (as prepared in Section 2.3) at $0-5^{\circ} \mathrm{C}$ for $24 \mathrm{~h}$. The resulting dark-red resin was filtered, washed with water, and dried in air. Figure 1 present the proposed resin structure.

2.5. Column Preparation. A cylindrically shaped polyvinyl chloride minicolumn $(3.50 \mathrm{~cm} \times 4.0 \mathrm{~mm}$ i.d. $)$ was packed with $100 \mathrm{mg}$ of the XAD-4/Br-TAO resin. Plastic foams were fixed at both ends of the minicolumn to prevent material losses. The minicolumn was initially washed with $2.0 \mathrm{~mol} \mathrm{~L}^{-1}$ nitric acid solution and deionized water until the effluent was free of acid. It was found that these minicolumns could be

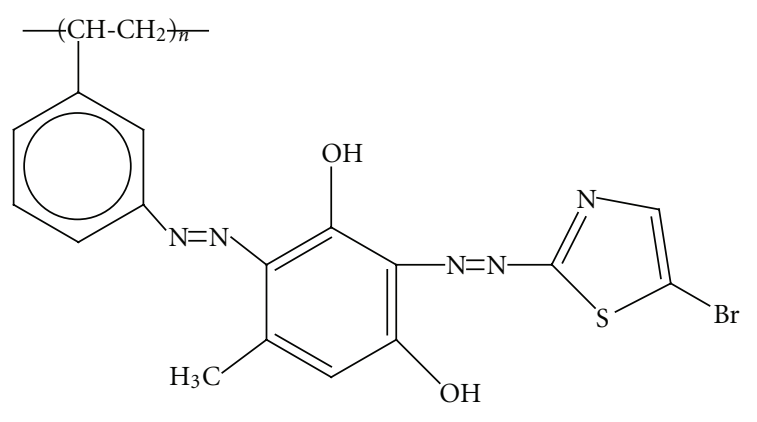

Figure 1: Proposed resin stucture.

used repeatedly for at least 500 operational cycles without efficiency damage of extraction capacity. The efficiency of the column was controlled by verification of its extraction performance after this column was used by a 50 extraction/elution cycle.

2.6. Sample Collection. Samples of produced formation waters were directly collected from offshore platforms in the Brazilian Northeast. Polyethylene flasks were used that had been previously decontaminated with nitric acid solution $(10 \%)$ and rinsed with ultra-pure water. After sampling, the samples were filtered through a membrane (pore diameter of $0.45 \mu \mathrm{m}$ ) using a vacuum system to remove suspended particulate material. Afterwards, samples were acidified to $\mathrm{pH} 2$ with nitric acid and stored at $6^{\circ} \mathrm{C}$.

2.7. Solid-Phase Extraction Optimization. The solid-phase extraction optimization procedure for the five trace metals studied was carried out using a Doehlert design [24-26] involving three variables: sample $\mathrm{pH}$, sampling flow rate, and buffer concentration. These variables were chosen due their great effect on the solid-phase extraction system as verified by previous experiments. The analytical response was counts/s. Experimental errors were estimated by triplicate analysis of the experiment, corresponding to the central point. $5.0 \mu \mathrm{g} \mathrm{L}^{-1} \mathrm{Co}, \mathrm{Cd}, \mathrm{Pb}, \mathrm{Ni}$, and $\mathrm{Cu}$ solutions with $10 \%$ salinity were used in all optimization experiments.

Responses for experimental design were obtained by evaluating the analytical signal of each element. To optimize a procedure that satisfies an efficient simultaneous extraction of all elements of interest, an overall response (OR) approach was adopted. The overall response is given by the following expression:

$$
\mathrm{OR}=\left[\frac{\mathrm{R}\left(X_{1}\right)}{\mathrm{LS}\left(X_{1}\right)}+\frac{\mathrm{R}\left(X_{2}\right)}{\mathrm{LS}\left(X_{2}\right)}+\cdots+\frac{\mathrm{R}\left(X_{n}\right)}{\mathrm{LS}\left(X_{n}\right)}\right]
$$

where $\mathrm{R}\left(X_{n}\right)$ is the analytical signal to element $n$ in a particular experiment and $\operatorname{LS}\left(X_{n}\right)$ is the maximum signal in the set of experiments for element $n$. The statistically significant effect of the variables was studied and interactions among them were evaluated by applying analysis of variance (ANOVA) using the Statistica software for Windows [27]. 
TABle 2: Doehlert experimental design for solid-phase extraction optimization.

\begin{tabular}{lccccccccc}
\hline $\begin{array}{l}\text { Experiment } \\
\text { number }\end{array}$ & Sample pH & $\begin{array}{l}\text { Sample flow } \\
\left.\text { rate }(\mathrm{mL} \mathrm{min})^{-1}\right)\end{array}$ & \multicolumn{2}{c}{$\begin{array}{l}\text { Buffer concentration } \\
\left(\mathrm{mol} \mathrm{L}^{-1}\right)\end{array}$} & $\mathrm{Cu}$ & $\mathrm{Ni}$ & $\mathrm{Pb}$ & $\mathrm{Cd}$ & $\mathrm{Co}$ \\
\hline 1 & 7.0 & 7.2 & 0.0300 & 77.13 & 83.53 & 76.60 & 74.16 & 76.00 & 3.89 \\
2 & 6.0 & 6.0 & 0.0200 & 73.64 & 83.70 & 81.95 & 80.27 & 82.34 & 4.04 \\
3 & 6.0 & 6.0 & 0.0400 & 77.06 & 85.66 & 83.57 & 84.62 & 84.04 & 4.17 \\
4 & 8.0 & 6.0 & 0.0200 & 82.22 & 91.45 & 94.58 & 96.56 & 84.96 & 4.52 \\
5 & 8.0 & 6.0 & 0.0400 & 84.75 & 92.32 & 95.61 & 97.40 & 85.90 & 4.58 \\
6 & 5.0 & 4.8 & 0.0300 & 98.04 & 82.70 & 54.75 & 19.76 & 84.78 & 3.42 \\
7.1 & 7.0 & 4.8 & 0.0300 & 84.73 & 93.00 & 90.97 & 89.89 & 88.67 & 4.50 \\
7.2 & 7.0 & 4.8 & 0.0300 & 86.55 & 94.45 & 89.02 & 88.05 & 86.39 & 4.47 \\
7.3 & 7.0 & 4.8 & 0.0300 & 89.42 & 94.11 & 88.28 & 90.52 & 94.30 & 4.59 \\
8 & 9.0 & 4.8 & 0.0300 & 72.56 & 104.97 & 99.10 & 100.42 & 95.48 & 4.74 \\
9 & 6.0 & 3.6 & 0.0200 & 93.95 & 90.96 & 93.70 & 95.725 & 82.78 & 4.60 \\
10 & 6.0 & 3.6 & 0.0400 & 94.19 & 91.84 & 94.68 & 97.42 & 89.12 & 4.70 \\
11 & 8.0 & 3.6 & 0.0200 & 92.83 & 99.62 & 95.20 & 97.59 & 94.94 & 4.83 \\
12 & 8.0 & 3.6 & 0.0400 & 96.49 & 102.78 & 98.02 & 100.03 & 96.15 & 4.96 \\
13 & 7.0 & 2.4 & 0.0300 & 91.53 & 101.05 & 90.89 & 94.36 & 94.24 & 4.74 \\
\hline
\end{tabular}

OR, overall response.

TABLe 3: Analysis of variance.

\begin{tabular}{lccccc}
\hline & SS & $d f$ & MS & $F$ & Tabulated $F$ \\
\hline Regression & 2.196 & 9 & 0.2440 & 4.77 \\
Residuals & 0.1037 & 5 & 0.02074 & 8.19 \\
Lack of Fit & 0.095875 & 3 & 0.03196 & 0.003900 \\
Pure Error & 0.007800 & 2 & & 19.16 \\
Total SS & 2.300 & 14 & & \\
\hline
\end{tabular}

SS: sum of square; $d f$ : degree of freedom; MS: media of square; F: Fischer distribution.

2.8. General Procedure after the Optimization Process. For solid-phase extraction, 25 or $50 \mathrm{~mL}$ of the sample was adjusted to $\mathrm{pH} 8.0$ using a TRIS buffer solution for a final concentration of $0.040 \mathrm{~mol} \mathrm{~L}^{-1}$. This solution was then pumped through a minicolumn loaded with XAD-4/Br-TAO resin at $3.6 \mathrm{~mL} \mathrm{~min}^{-1}$. After this step, the minicolumn was washed with TRIS buffer $(5 \mathrm{~mL})$ to eliminate residual salt. Trace metals adsorbed on this solid-phase were re-extracted with $\mathrm{HNO}_{3}$ solution $(1 \mathrm{~mol} \mathrm{~L}-1,2 \mathrm{~mL}$ ) and collected in graduated polyethylene flasks. A solution of internal standards (Sc, Ge, Rh, and In) was added to the eluate for a final concentration of $50 \mu \mathrm{g} \mathrm{L}^{-1}$. The volume was set to $5 \mathrm{~mL}$ and the determination of the target elements was performed by ICP-MS.

2.9. Evaluation of Sample Salinity on the Solid-Phase Extraction Efficiency. The sample salinity was then evaluated with respect to its influence on the solid-phase extraction and the residual salinity of the eluate on the nebulization process and its consequence on the measured signal. $5 \mu \mathrm{g} \mathrm{L}^{-1}$ solutions of $\mathrm{Co}, \mathrm{Cd}, \mathrm{Pb}, \mathrm{Ni}$, and $\mathrm{Cu}$, in the presence of different $\mathrm{NaCl}$ concentrations (salinities of $0,10,20,30,40,50,60$, and $100 \%$ ), were submitted to the separation/preconcentration procedure described in Section 2.8 and recovery was evaluated.

\section{Results and Discussion}

3.1. Solid-Phase Extraction Optimization. Optimization of the extraction process was carried out using Doehlert design as a multivariate methodology to obtain individual results for each element. There was an observed tendency for efficient solid-phase extraction in a common region for all metals of interest. For feasible optimization of extraction conditions for multiple elements in a single experiment, overall response was used. The overall response can be related to the five individual responses according to (1). The maximum overall response (OR) obtained was 4.96, in the set of thirteen experiments that compose the Doehlert matrix (Table 2).

A second-order polynomial model was fit to the overall response data, in order to depict the experimental region and determine the optimum conditions. Analysis of variance (ANOVA) was used to evaluate the resulting mathematical model, using a 95\% confidence interval (Table 3). Comparison of the tabulated $F$ value (Fischer distribution) and the value obtained by division of the media of square 


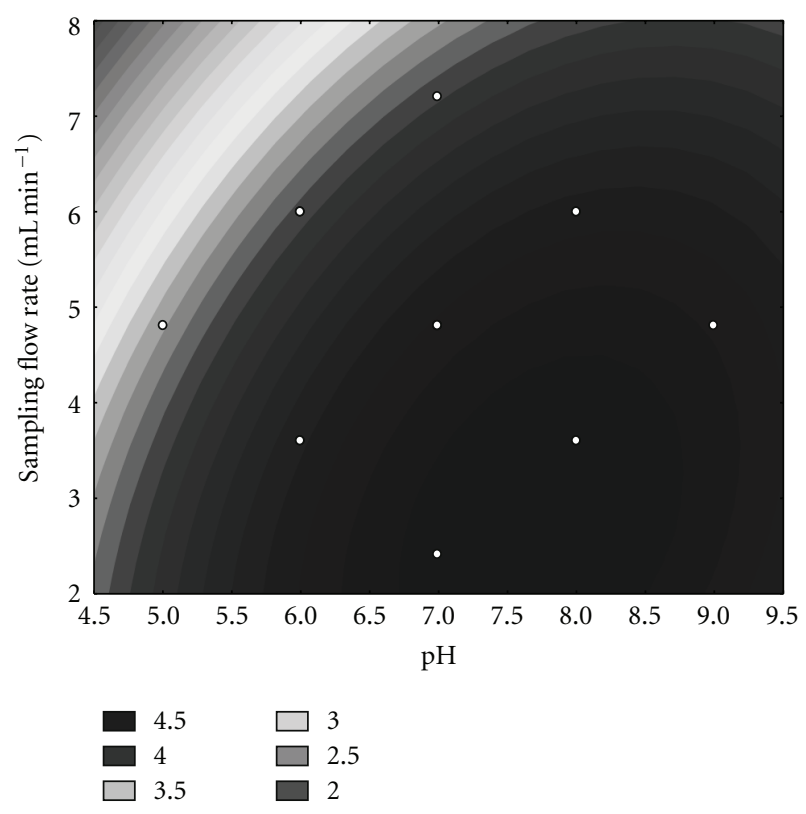

(a)

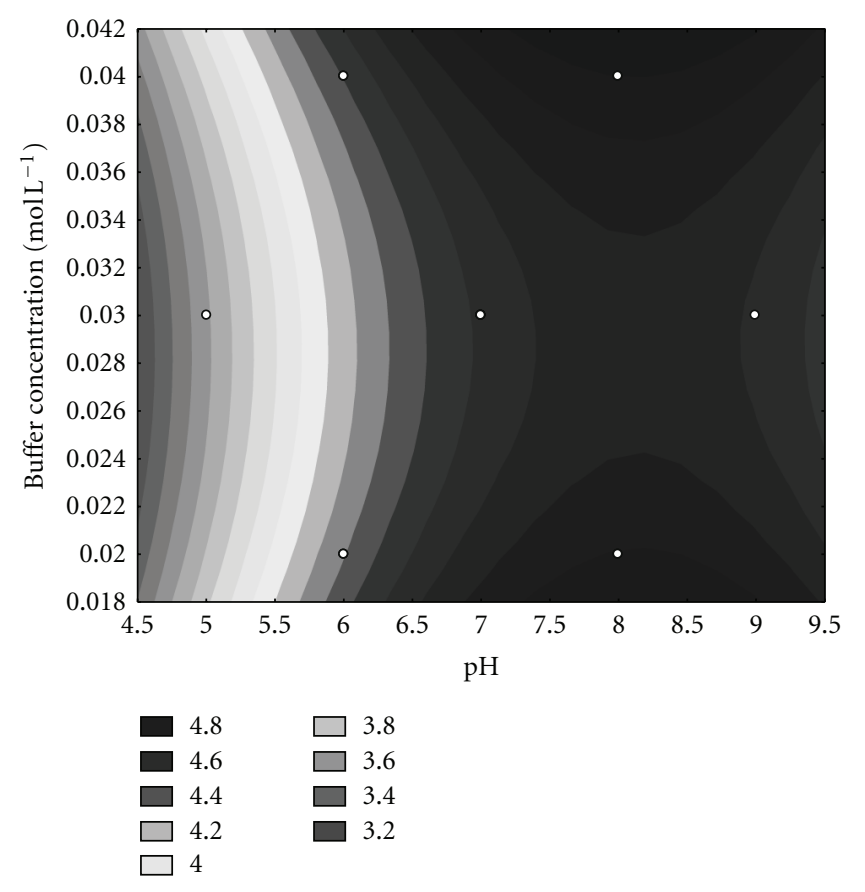

(b)

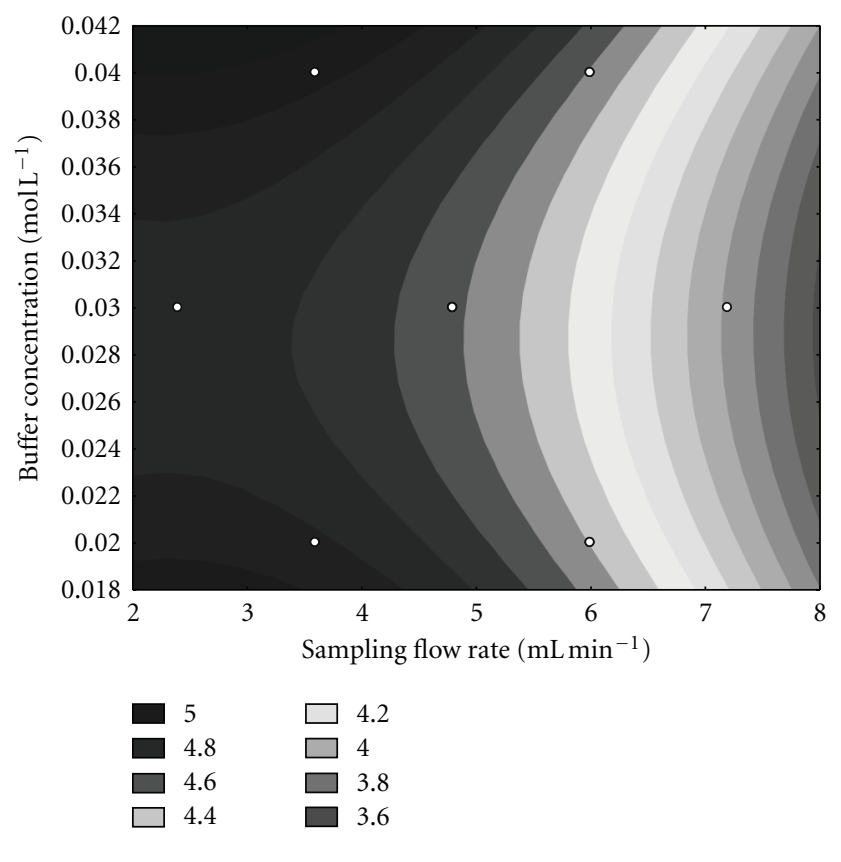

(c)

Figure 2: Contour graphs profiles using overall response. (a) Sampling flow rate $\times \mathrm{pH}$, (b) $\mathrm{pH} \times$ buffer concentration, and (c) sampling flow rate $\times$ buffer concentration.

of regression $\left(\mathrm{MS}_{\mathrm{reg}}\right)$ by the media of square of residual $\left(\mathrm{MS}_{\text {res }}\right)$ confirms that the regression is significant $\left(F_{\text {tabulated }}>\right.$ $\left.F_{\text {calculated }}\right)$. Additionally, comparison of the tabulated $\mathrm{F}$ value and the value obtained by division of the media of square of lack of fit $\left(\mathrm{MS}_{\text {lof }}\right)$ by the media of square of pure error $\left(\mathrm{MS}_{\mathrm{pe}}\right)$ shows that the model is well adjusted to experimental data $\left(F_{\text {tabulated }}>F_{\text {calculated }}\right)$.
All variables showed a significant effect for the elements studied; however, sample $\mathrm{pH}$ and sampling flow rate were most significant. Specifically, the extraction procedure is favored when the sample $\mathrm{pH}$ is increased to a sufficiently high level and when the flow rate is decreased to the minimum level. Figure 2 shows profiles of these surfaces (as contour graphs) after fitting to a quadratic model for the overall 
TABLE 4: Results for two certificated reference materials of waters $\left(\mu \mathrm{g} \mathrm{L}^{-1}, N=3\right)$.

\begin{tabular}{lcccc}
\hline Analyte & \multicolumn{2}{c}{ SLEW-3 (NRCC) } & \multicolumn{2}{c}{ SLRS-4 (NRCC) } \\
& Certified & Obtained & Certified & Obtained \\
\hline $\mathrm{Co}$ & $0.042 \pm 0.010$ & $0.041 \pm 0.004$ & $0.033 \pm 0.006$ & $0.032 \pm 0.003$ \\
$\mathrm{Cd}$ & $0.048 \pm 0.004$ & $0.047 \pm 0.001$ & $0.012 \pm 0.002$ & $<0.014$ \\
$\mathrm{~Pb}$ & $0.0090 \pm$ & & & \\
& 0.0014 & $<0.010$ & $0.086 \pm 0.007$ & $0.083 \pm 0.004$ \\
$\mathrm{Cu}$ & $1.55 \pm 0.12$ & $1.59 \pm 0.06$ & $1.81 \pm 0.08$ & $1.74 \pm 0.038$ \\
$\mathrm{Ni}$ & $1.23 \pm 0.07$ & $1.29 \pm 0.05$ & $0.67 \pm 0.08$ & $0.62 \pm 0.066$ \\
\hline
\end{tabular}

response. These surfaces are characterized by a saddle point. Thus, by visual inspection of the response surface, 8.0, $0.040 \mathrm{~mol} \mathrm{~L}^{-1}$, and $3.6 \mathrm{~mL} \mathrm{~min}^{-1}$ were chosen as the optimum values for the sample $\mathrm{pH}$, final buffer concentration, and sampling flow rate, respectively.

3.2. Evaluation of Sample Salinity on the Trace Metal Extraction. Salinity can widely vary in PFW, with values as high as $200 \%$. High salt concentrations can cause serious problems in ICP-MS due to severe interferences and instrumental damages. Separation procedures, such as solid-phase extraction, can eliminate the complex matrix by transferring target analytes to a simpler solution before determination. Thus, solutions with salinities ranging from 0 to $100 \%$ o $(\mathrm{NaCl}$ solutions) were extracted at the optimum conditions and the recovery for each trace metal was evaluated. The results suggest that salinities as high as $100 \%$ do not affect trace metals extraction showing that matrix interference has been eliminated in the separation step.

3.3. Analytical Features of the Method. The analytical features of the proposed procedure were assessed after a variable optimization. The concentrations of the analytical standards for the preconcentration procedure ranged between 0.05 and $5 \mu \mathrm{g} \mathrm{L}^{-1}$ (unless for copper which was between 0.5 and $\left.5 \mu \mathrm{g} \mathrm{L}^{-1}\right)$. Without this preconcentration step, the concentrations of the calibration standards ranged between 1 and $100 \mu \mathrm{g} \mathrm{L}^{-1}$. Parameters of analytical curve obtained after preconcentration/separation procedure are presented in Table 5 .

The limit of detection (LOD) and the limit of quantification (LOQ) are defined as LOD $=3 \sigma / S$ and LOQ $=10 \sigma / S$, respectively, where $S$ is the slope of the analytical curve and $\sigma$ is the standard deviation of ten consecutive measurements of the blank signal. For $50.0 \mathrm{~mL}$ of sample solution used in the preconcentration step, limits of detection of $0.72,4.2$, 3.0, 3.3, and $105 \mathrm{ng} \mathrm{L}^{-1}$, limits of quantification of 2.4, 14, 10, 11 , and $350 \mathrm{ng} \mathrm{L}^{-1}$, and precision (repeatability) expressed as relative standard deviation $\left(n=10,5.0 \mu \mathrm{g} \mathrm{L}^{-1}\right)$ of $1.4,1.3$, $2.8,0.9$, and $1.9 \%$ were obtained for $\mathrm{Co}, \mathrm{Cd}, \mathrm{Pb}, \mathrm{Ni}$, and $\mathrm{Cu}$, respectively.

The accuracy of the proposed procedure was assessed by analysis of the following certified reference materials: NRCCSLEW-3 (Estuarine Water) and NRCC-SLRS-4 (Riverine
TABLE 5: Parameters of analytical curve obtained after application of the developed preconcentration/separation procedure.

\begin{tabular}{lcc}
\hline Metal & Analytical curve & $R$ \\
\hline $\mathrm{Co}$ & $y=111050 \mathrm{C}_{\mathrm{Co}}+29135$ & 0.9955 \\
$\mathrm{Cd}$ & $y=44942 \mathrm{C}_{\mathrm{Cd}}+7216$ & 0.9989 \\
$\mathrm{~Pb}$ & $y=81383 \mathrm{C}_{\mathrm{Pb}}+1039$ & 0.9983 \\
$\mathrm{Cu}$ & $y=82209 \mathrm{C}_{\mathrm{Cu}}+3603$ & 0.9985 \\
$\mathrm{Ni}$ & $y=135611 \mathrm{C}_{\mathrm{Ni}}+22524$ & 0.9981 \\
\hline
\end{tabular}

Water). Results are presented in Table 4. The values obtained in this study agree well with the certified value reported for these certified reference materials. $t$-test paired was applied to evaluation of these results. At the $95 \%$ confidence level, the difference of the population means is not significantly different for both certified and found results. Recoveries between 88 and 109\% were found for studied meals after spike test (Table 6).

3.4. Application. The developed procedure was applied to four production formation waters obtained from offshore oil platforms in the Brazilian Northeast. These results are summarized in Table 6 . The determination of trace metal concentrations is of environmental concern due to the large volume of water produced with oil (as much as 10 times the oil production) that is ultimately discharged into the sea. Brazilian legislation (CONAMA Resolution 357/2005) [29] establishes that the maximum concentrations allowed to be discharged in saline water class I (waters for more restrictive uses) are Cd $5 \mu \mathrm{gL}^{-1}$, Ni $25 \mu \mathrm{gL}^{-1}, \mathrm{~Pb}$ $10 \mu \mathrm{g} \mathrm{L}^{-1}$, and $\mathrm{Cu} 5 \mu \mathrm{g} \mathrm{L}^{-1}$ (Co concentration is not yet considered in the legislation). From Table 6 it is observed that the trace metal levels in the production formation waters analyzed did not exceed the Brazilian guidelines. The proposed method allows determining these five metals in lower limit of quantification than other methods previously published $[4,28,30]$. Also an online solid-phase extraction offers some additional advantage, in comparison to other methods, such as reutilization of solid phase for several cycles, simplicity, elimination of matrix effect, and low reagent consumption.

\section{Conclusions}

Through application of Doehlert design conditions, the simultaneous separation and preconcentration of $\mathrm{Co}, \mathrm{Cd}, \mathrm{Pb}$, $\mathrm{Cu}$, and $\mathrm{Ni}$ were optimized. The influence of the sample salinities in ICP-MS was suppressed by matrix separation, employing a minicolumn of XAD-4/Br-TAO for solid-phase extraction.

The developed procedure for separation/preconcentration and determination of trace metals in saline waters was applied for both CRMs and produced formation waters, showing good accuracy. The produced formation water samples analyzed showed very low levels of trace metals of environmental concern. 
TABLE 6: Results for the petroleum produced formation waters analyzed by using the solid-phase extraction and ICP-MS measurements $\left(\mu \mathrm{g} \mathrm{L} \mathrm{L}^{-1}, N=3\right.$, mean \pm standard deviation).

\begin{tabular}{lcccccc}
\hline Samples & Salinity $(\%)$ & Co & Cd & Pb & Cu & Ni \\
\hline PFW 1 & 50 & $0.051 \pm 0.001$ & $0.108 \pm 0.002$ & $<0.010$ & $<0.35$ & $0.162 \pm 0.005$ \\
PFW 2 & 62 & $0.072 \pm 0.009$ & $0.182 \pm 0.002$ & $0.403 \pm 0.005$ & $3.55 \pm 0.02$ & $<0.011$ \\
PFW 3 & 10 & $<0.003$ & $<0.014$ & $<0.010$ & $2.2 \pm 0.2$ & $<0.011$ \\
PFW 4 & 62 & $<0.003$ & $<0.014$ & $<0.010$ & $<0.35$ & $<0.011$ \\
PFW 4 + metals* & 62 & $0.088 \pm 0.005$ & $0.093 \pm 0.005$ & $0.091 \pm 0.008$ & $0.513 \pm 0.007$ & $0.109 \pm 0.004$ \\
Recovery (\%)** & - & 88 & 93 & $0-1.9$ & $0.057-0.80$ & 103 \\
Previous works** & $15-120$ & $0-3.5$ & $0-3.7$ & 109 \\
\hline
\end{tabular}

* Analytes added for a final concentration of $0.100 \mu \mathrm{g} \mathrm{L}^{-1}$ in the sample unless for copper which final concentration was $0.5 \mu \mathrm{g} \mathrm{L}{ }^{-1}$; ** Recovery from spike test in the PFW 4 sample; ${ }^{* * *}$ Concentration and salinity range found in previous works $[4,28]$.

\section{Acknowledgments}

The authors gratefully acknowledge Conselho Nacional de Desenvolvimento Científico e Tecnológico (CNPq), Coordenação de Aperfeiçoamento de Pessoal de Nível Superior (CAPES), Fundação Carlos Chagas Filho de Amparo à Pesquisa do Estado do Rio de Janeiro (FAPERJ), and Fundação de Amparo à Pesquisa do Estado da Bahia (FAPESB) for financial support and fellowships.

\section{References}

[1] M. C. T. Scholten, C. C. Karman, and S. Huwer, "Ecotoxicological risk assessment related to chemicals and pollutants in off-shore oil production," Toxicology Letters, vol. 112-113, pp. 283-288, 2000.

[2] P. Ekins, R. Vanner, and J. Firebrace, "Zero emissions of oil in water from offshore oil and gas installations: economic and environmental implications," Journal of Cleaner Production, vol. 15, no. 13-14, pp. 1302-1315, 2007.

[3] T. I. R. Utvik, "Chemical characterisation of produced water from four offshore oil production platforms in the North Sea," Chemosphere, vol. 39, no. 15, pp. 2593-2606, 1999.

[4] M. A. Bezerra, S. Mitihiro do Nascimento Maêda, E. P. Oliveira, M. de Fátima Batista de Carvalho, and R. E. Santelli, "Internal standardization for the determination of cadmium, cobalt, chromium and manganese in saline produced water from petroleum industry by inductively coupled plasma optical emission spectrometry after cloud point extraction," Spectrochimica Acta Part B, vol. 62, no. 9, pp. 985-991, 2007.

[5] E. P. Oliveira, R. E. Santelli, and R. J. Cassella, "Direct determination of lead in produced waters from petroleum exploration by electrothermal atomic absorption spectrometry X-ray fluorescence using Ir-W permanent modifier combined with hydrofluoric acid," Analytica Chimica Acta, vol. 545, no. 1, pp. 85-91, 2005.

[6] J. M. Neff, S. Johnsen, T. K. Frost, T. I. R. Utvik, and G. S. Durell, "Oil well produced water discharges to the North Sea. Part II: comparison of deployed mussels (Mytilus edulis) and the DREAM model to predict ecological risk," Marine Environmental Research, vol. 62, no. 3, pp. 224-246, 2006.

[7] M. S. Jiménez, R. Velarte, and J. R. Castillo, "Performance of different preconcentration columns used in sequential injection analysis and inductively coupled plasma-mass spectrometry for multielemental determination in seawater," Spectrochimica Acta Part B, vol. 57, no. 3, pp. 391-402, 2002.
[8] M. S. Jiménez, R. Velarte, and J. R. Castillo, "New approaches to the direct analysis of highly saline samples by FIA-ICP-MS," Atomic Spectroscopy, vol. 21, no. 5, pp. 156-164, 2000.

[9] H. H. Chen and D. Beauchemin, "Determination of trace metals in saline water using flow injection on-line precipitation coupled with inductively coupled plasma mass spectrometry," Journal of Analytical Atomic Spectrometry, vol. 16, no. 12, pp. 1356-1363, 2001.

[10] D. Kara, A. Fisher, and S. J. Hill, "Preconcentration and determination of trace elements with 2,6-diacetylpyridine functionalized Amberlite XAD-4 by flow injection and atomic spectroscopy," Analyst, vol. 130, no. 11, pp. 1518-1523, 2005.

[11] M. Nicolaï, C. Rosin, N. Tousset, and Y. Nicolai, "Trace metals analysis in estuarine and seawater by ICP-MS using on line preconcentration and matrix elimination with chelating resin," Talanta, vol. 50, no. 2, pp. 433-444, 1999.

[12] V. Camel, "Solid phase extraction of trace elements," Spectrochimica Acta Part B, vol. 58, no. 7, pp. 1177-1233, 2003.

[13] V. A. Lemos, L. S. G. Teixeira, M. D. A. Bezerra et al., "New materials for solid-phase extraction of trace elements," Applied Spectroscopy Reviews, vol. 43, no. 4, pp. 303-334, 2008.

[14] M. A. Bezerra, W. N. L. dos Santos, V. A. Lemos, M. D. G. A. Korn, and S. L. C. Ferreira, "On-line system for preconcentration and determination of metals in vegetables by inductively coupled plasma optical emission spectrometry," Journal of Hazardous Materials, vol. 148, no. 1-2, pp. 334-339, 2007.

[15] V. A. Lemos, M. A. Bezerra, and F. A. C. Amorim, "Online preconcentration using a resin functionalized with 3,4dihydroxybenzoic acid for the determination of trace elements in biological samples by thermospray flame furnace atomic absorption spectrometry," Journal of Hazardous Materials, vol. 157, no. 2-3, pp. 613-619, 2008.

[16] V. A. Lemos, M. S. Santos, E. S. Santos et al., "Application of polyurethane foam as a sorbent for trace metal preconcentration-a review," Spectrochimica Acta Part B, vol. 62, no. 1, pp. 4-12, 2007.

[17] F. Xie, X. Lin, X. Wu, and Z. Xie, "Solid phase extraction of lead (II), copper (II), cadmium (II) and nickel (II) using gallic acid-modified silica gel prior to determination by flame atomic absorption spectrometry," Talanta, vol. 74, no. 4, pp. 836-843, 2008.

[18] V. A. Lemos, C. G. Novaes, A. D. S. Lima, and D. R. Vieira, "Flow injection preconcentration system using a new functionalized resin for determination of cadmium and nickel in tobacco samples," Journal of Hazardous Materials, vol. 155, no. 1-2, pp. 128-134, 2008. 
[19] V. A. Lemos, D. R. Vieira, C. G. Novaes, M. E. Rocha, M. S. Santos, and R. T. Yamaki, "Preconcentration systems using polyurethane foam/Me-BDBD for determination of copper in food samples," Microchimica Acta, vol. 153, no. 3-4, pp. 193 201, 2006.

[20] E. V. Alonso, M. T. S. Cordero, A. G. de Torres, P. C. Rudner, and J. M. C. Pavón, "Mercury speciation in sea food by flow injection cold vapor atomic absorption spectrometry using selective solid phase extraction," Talanta, vol. 77, no. 1, pp. 5359, 2008.

[21] V. A. Lemos, P. X. Baliza, A. L. de Carvalho, R. V. Oliveira, L. S. G. Teixeira, and M. A. Bezerra, "Development of a new sequential injection in-line cloud point extraction system for flame atomic absorption spectrometric determination of manganese in food samples," Talanta, vol. 77, no. 1, pp. 388393, 2008.

[22] S. L. C. Ferreira, M. G. M. Andrade, I. P. Lobo, and A. C. S. Costa, "2-(2-thiazolylazo)-p-cresol(TAC) as a ragent for the spectrophotometric determination of lead(II)," Analytical Letters, vol. 24, no. 9, pp. 1675-1684, 1991.

[23] E. M. Gama, A. da Silva Lima, and V. A. Lemos, "Preconcentration system for cadmium and lead determination in environmental samples using polyurethane foam/Me-BTANC," Journal of Hazardous Materials, vol. 136, no. 3, pp. 757-762, 2006.

[24] M. A. Bezerra, R. E. Santelli, E. P. Oliveira, L. S. Villar, and L. A. Escaleira, "Response surface methodology (RSM) as a tool for optimization in analytical chemistry," Talanta, vol. 76, no. 5, pp. 965-977, 2008.

[25] S. L. C. Ferreira, W. N. L. Dos Santos, C. M. Quintella, B. B. Neto, and J. M. Bosque-Sendra, "Doehlert matrix: a chemometric tool for analytical chemistry-review," Talanta, vol. 63, no. 4, pp. 1061-1067, 2004.

[26] M. D. A. Bezerra, A. L. B. Conceição, and S. L. C. Ferreira, "A pre-concentration procedure using cloud point extraction for the determination of manganese in saline effluents of a petroleum refinery by flame atomic absorption spectrometry," Microchimica Acta, vol. 154, no. 1-2, pp. 149-152, 2006.

[27] Statistica for Windows, Statsoft, Inc., Tulsa, Okla, USA, 1999.

[28] L. A. Escaleira, R. E. Santelli, E. P. Oliveira, M. F. B. de Carvalho, and M. A. Bezerra, "Preconcentration procedure for determining trace amounts of $\mathrm{Ni}, \mathrm{Cd}, \mathrm{Pb}$ and $\mathrm{Cu}$ in highsalinity waters after cloud-point extraction," International Journal of Environmental Analytical Chemistry, vol. 89, no. 7, pp. 515-527, 2009.

[29] CONAMA. Conselho Nacional do Meio Ambiente, Ministério do Meio Ambiente, Resolution 357/2005, 17 de março de 2005, Brasília, Brazil, 2005, http://www.mma.gov.br/.

[30] E. P. Oliveira, L. Yang, R. E. Sturgeon et al., "Determination of trace metals in high-salinity petroleum produced formation water by inductively coupled plasma mass spectrometry following on-line analyte separation/preconcentration," Journal of Analytical Atomic Spectrometry, vol. 26, pp. 578-585, 2011. 


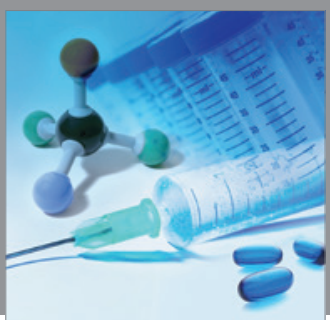

International Journal of

Medicinal Chemistry

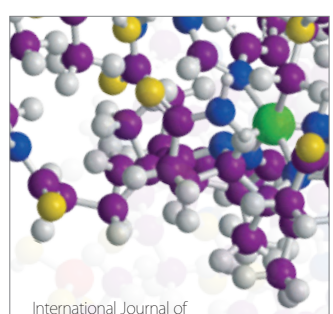

Carbohydrate Chemistry

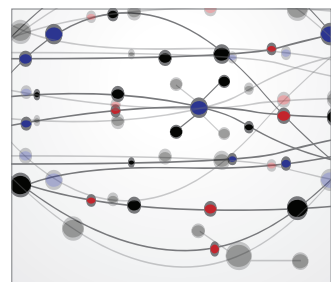

The Scientific World Journal
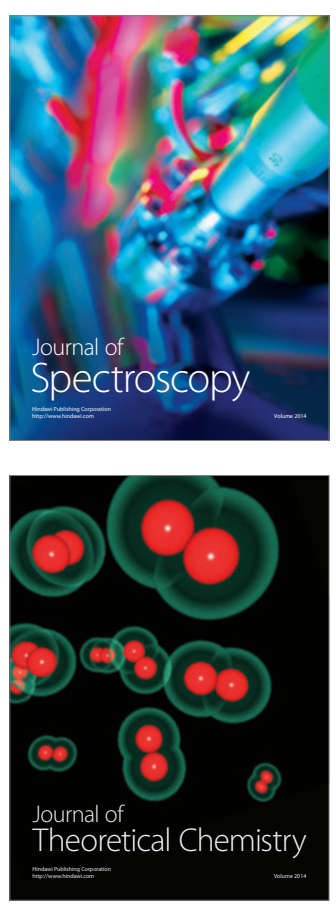
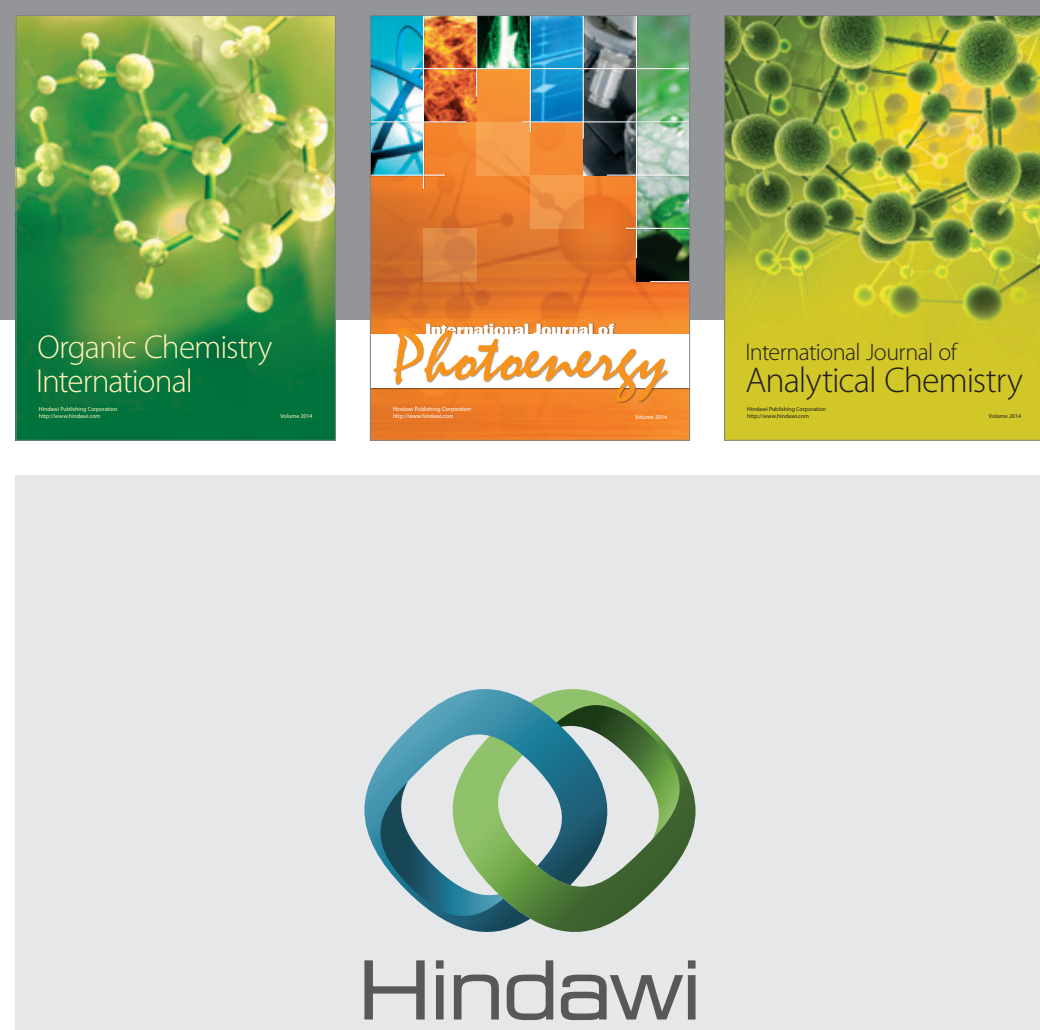

Submit your manuscripts at

http://www.hindawi.com
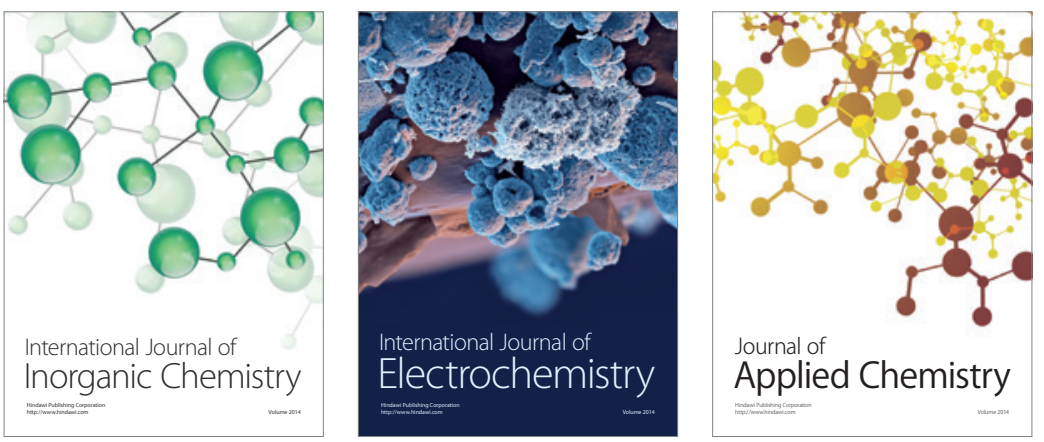

Journal of

Applied Chemistry
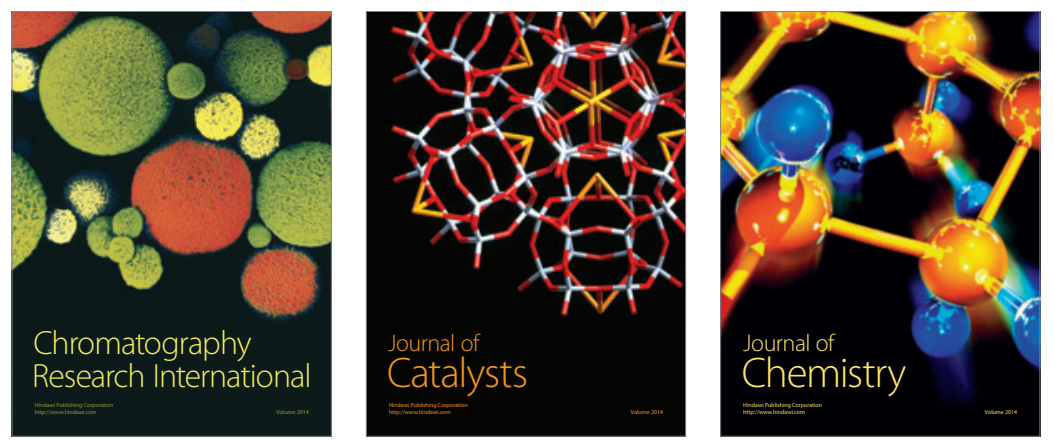
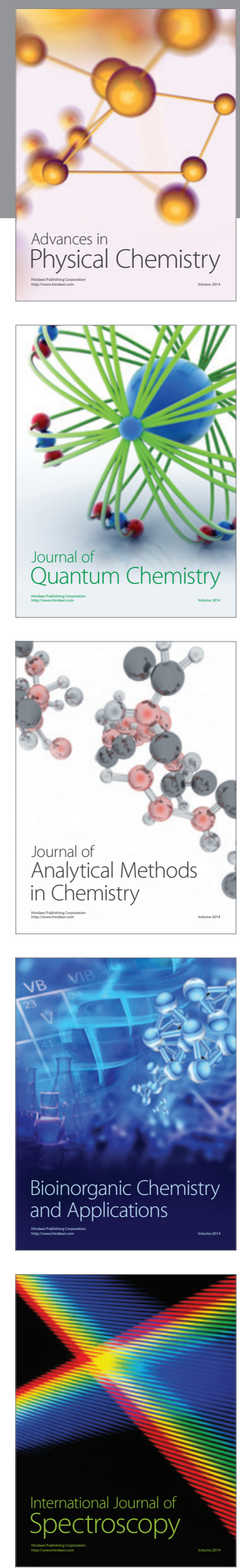